\title{
EREBEA
}

Revista de Humanidades

y Ciencias Sociales

Núm. 8 (2018), pp. 9-22

ISSN: 0214-0691

\section{De LA LEVE EXISTENCIA (INCLUSO LEGAL)} Del Patrimonio InMaterial

\author{
Francesc Llop i Bayo
}

Antropólogo

RESUMEN

El Patrimonio Inmaterial, de reciente reconocimiento, es la hermana pobre del patrimonio, la categoría menos apreciada y protegida. Se da la contradicción que todos dicen protegerlo, pero en realidad está sujeto a limitaciones y faltas de protección que el patrimonio reconocido, especialmente el monumental no tiene.

Palabras Clave

Patrimonio inmaterial; protección legal.
KeYwords

Intangible heritage; legal protection.

Fecha de recepción: 22 de sept. de 2018

Fecha de aceptación: 1 de oct. de 2018

\section{ABSTRACT}

Newly recognized Intangible Heritage is the poor sister of the heritage, the least appreciated and protected category. There is a contradiction that everyone claims to protect it, but in reality it is subject to limitations and lack of protection that recognized patrimony, especially the monumental one does not have. 
El Patrimonio Inmaterial (o Intangible, que otros lo llaman así) está de moda. En general porque cuesta poco de proteger, se tramita de manera rápida, y da prestigio a los que participan de él. Pero se trata de un patrimonio menor, mal comprendido, peor protegido, y (casi) siempre discriminado. Vayamos por partes.

Hace una treintena de años, la UNESCO descubrió el patrimonio intangible, como lo llaman ellos, para tratar de equilibrar la balanza entre países ricos y países pobres. Los países ricos en patrimonio material reconocido como patrimonio mundial por la UNESCO son esencialmente los del norte del Mediterráneo, no sólo porque fueron la cuna de las grandes civilizaciones de la antigüedad occidental (Grecia, Roma, el medievo gótico) cuanto que su potente aparato administrativo funciona a la perfección para preparar expedientes impecables para el reconocimiento mundial. No es que los países del sur (en el sentido más amplio de la palabra) carezcan de patrimonio, que sí que lo tienen, y a menudo mucho más espectacular. Pero carecen de un aparato administrativo desarrollado, y de una clase política concienciada en proteger su patrimonio monumental. Habría que decir mejor en promocionar su patrimonio: si bien la Convención de la UNESCO nace sobre todo con la idea de proteger los monumentos primero, y más tarde los bienes intangibles que están en peligro, desde el primer mundo, sobre todo, se concibe el sello Patrimonio Mundial como una marca de calidad, o de excelencia como ahora se dice. En suma, como un reclamo para el turismo superficial y masivo que ahora nos caracteriza.

He dicho Patrimonio Mundial, que es la tradición exacta del inglés World Heritage utilizado por la UNESCO, aunque por nuestras tierras hispanohablantes, por motivos que aún se me escapan, la denominación habitual es Patrimonio de la Humanidad, posiblemente porque aún da más prestigio ese nombre global.

\section{LA PROTECCIÓN DEL PATRIMONIO INMATERIAL EN ESPAÑA}

Pasando a un campo mucho más concreto, la protección del patrimonio inmaterial ha sido siempre, en España, mucho más difusa e inconcreta. Bien es cierto que con la organización territorial en territorios autónomos, la gestión del patrimonio fue transferida desde los primeros momentos, pero la Ley del Patrimonio Histórico Español ${ }^{1}$ que sirvió - y sirve - de marco para las diferentes leyes

1 Ley 16/1985, de 25 de junio, del Patrimonio Histórico Español (BOE núm. 155 de 29-06$-1985$ 
autonómicas, no consideraba el patrimonio inmaterial con la misma protección que el resto. Mucho más tarde, en 2015, se le añade un inciso al artículo primero, que define qué bienes integran el Patrimonio Histórico Español diciendo que Asimismo, forman parte del Patrimonio Histórico Español los bienes que integren el Patrimonio Cultural Inmaterial, de conformidad con lo que establezca su legislación especial.

El patrimonio inmaterial es llamado en la ley original Patrimonio Etnográfico y así como se definen los bienes inmuebles o muebles de carácter etnográfico, cuando se llega al patrimonio inmaterial se propone una documentación, que nunca se llevó a cabo².

En nuestra actividad profesional, como técnico de etnología de la Generalitat Valenciana ${ }^{3}$ intentamos desde el principio que el patrimonio inmaterial fuese considerado similar al resto de patrimonio tangible (inmueble o mueble) lo que parecía una tarea imposible, a causa de los servicios jurídicos, que no querían igualar ambos conceptos.

He cambiado intencionadamente el orden habitual (se suele decir mueble e inmueble) porque también en este caso patrimonial hay unas prioridades. No sólo para los cuerpos jurídicos de la administración, sino para los gestores políticos e incluso para la población, un monumento es un edificio, lo más antiguo posible y de valor incuestionable. Y si es romano, o de los moros, mejor. Un objeto, aunque sea declarado a su vez BIC (Bien de Interés Cultural) no tiene una misma consideración. La reticencia, creemos que pasada, a incluir objetos muebles en la declaración de monumentos, es decir de Bienes Inmuebles de Interés Cultural, se justificaba porque todo lo que hay dentro de un monumento, forma parte del mismo. Sin embargo, en casos concretos de protección de bienes muebles, que formaban parte de un BIC Inmueble, pero que no estaban definidos en su declaración, nos decían, por el contrario, que se podía actuar sobre ellos sin el necesario control administrativo, porque no estaban protegidos explícitamente.

La reticencia para incluir el patrimonio intangible al mismo nivel que el resto, en la primera redacción de la Ley valenciana ${ }^{4}$ fue tan grande, que solamente en el

2 Artículo cuarenta y siete apartado tres: Se considera que tienen valor etnográfico y gozarán de protección administrativa aquellos conocimientos o actividades que procedan de modelos o técnicas tradicionales utilizados por una determinada comunidad. Cuando se trate de conocimientos o actividades que se hallen en previsible peligro de desaparecer, la Administración competente adoptará las medidas oportunas conducentes al estudio y documentación cientificos de estos bienes.

3 Probablemente fuimos, en 1988, el primer antropólogo trabajando para una comunidad autónoma, aunque nuestro trabajo era definido como técnico de etnología, utilizando la concepción francesa del término, más que la británica. Algo más tarde la Junta de Andalucía creó a su vez la misma plaza, que más tarde fue ampliada con varias personas más. Aún hoy (2018) más de la mitad de comunidades autónomas carecen de antropólogo o etnólogo en sus puestos de trabajo.

4 Ley 4/1998, de 11 de junio, del Patrimonio Cultural Valenciano. ( DOCV núm. 3267, de 18-06-1998, BOE núm 174, de 22-07-1998. 
último minuto, cuando ya había comenzado la discusión parlamentaria, se incluyó el patrimonio inmaterial con las mismas protecciones que el resto. Así figurará en cada una de las definiciones de la ley los bienes muebles, inmuebles e inmateriales del patrimonio cultural teniendo el patrimonio inmaterial los mismos niveles de protección que el resto (Bien de Interés Cultural, Inventario General, Bien de Relevancia Local, incluso la de bien susceptible de ser incluido en el inventario general). La ley valenciana, que ha tenido al menos cinco versiones diferentes, con diversas modificaciones que sirvieron sobre todo para delimitar y facilitar actividades urbanísticas en relación con el patrimonio inmueble, incluye también una peculiar consideración del patrimonio tecnológico. A pesar de las indicaciones de la ley ningún elemento ha sido reconocido, protegido y declarado como tal ${ }^{5}$. Parece que la intención era declarar algún sitio Web como patrimonio inmaterial tecnológico como el buscador dónde? creado por la Universitat Jaume I de Castelló, y que fue uno de los primeros utilizados, hasta la aparición y consolidación del todopoderosos Google, un tiempo más tarde. En cualquier caso, nunca se tuvo en cuenta este patrimonio tecnológico inmaterial.

Sin embargo esta costosa introducción del patrimonio inmaterial en la ley valenciana tenía un antecedente bien antiguo: el llamado Misteri d'Elx se declaraba el 15 de septiembre de 1931 como Monumento Nacional, mediante decreto publicado en la Gaceta de Madrid al día siguiente con la firma del presidente de la República. Pero no es menos cierto que esta rara avis no servía de ejemplo a los juristas ya que planteaban la dificultad de protección del patrimonio inmaterial, puesto que depende de la voluntad de personas, a las que no se puede obligar. Luego volveremos sobre estas distintas valoraciones de los diferentes patrimonios.

No todas las leyes autonómicas protegen el patrimonio antropológico, etnológico o inmaterial del mismo modo que el mueble o inmueble. Así Andalucía incluye los bienes inmateriales en un inventario, sin una protección específica añadida. Catalunya por el contrario ha declarado diversos bienes inmateriales como Bé Nacional d'Interès Cultural de una forma tan genérica que tampoco incide en su protección. Los constantes acontecimientos políticos y sociales de los últimos tiempos en tierras catalanas han ensombrecido una peculiar declaración genérica del Govern de la Generalitat declarando los toques de campana como elemento patrimonial ${ }^{6}$ en la última reunión antes de la declaración virtual, y acaso inmaterial de la República Catalana el 27 de octubre de 2018. Pero si la inclusión en un Inventario Etnológico de Andalucía tiene escasos efectos legales, tampoco parece tener muchos más esa declaración catalana genérica de los toques de cam-

5 Articulo 1.1 Los Bienes Inmateriales de Naturaleza Tecnológica que constituyan manifestaciones relevantes o hitos de la evolución tecnológica de la Comunitat Valenciana son, asi mismo, elementos integrantes del patrimonio cultural valenciano.

6 ACORD GOV/150/2017, de 24 d'octubre, pel qual es declaren els tocs de campana com a Element Festiu Patrimonial d'Interès Nacional. 
panas, considerándolos como Elemento Festivo Patrimonial. ¿Quedan incluidos los toques diarios, los toques del reloj, los toques de muerto? Nadie lo sabe, y los jueces, como veremos luego, incluso en Catalunya, siguen supeditando el patrimonio inmaterial declarado incluso declarado a normas legales inferiores como los reglamentos municipales del ruido.

\section{LA PROTECCIÓN DE LA APARIENCIA}

Con el patrimonio inmaterial ocurre, en cierto modo, lo mismo que con el patrimonio industrial. Que todos dicen protegerlo, pero a la hora de la verdad, nadie pasa de las declaraciones de intenciones a los hechos.

Pensemos que en un sentido amplio, patrimonio industrial no son solamente las chimeneas, ni siquiera las fábricas sino el tejido social que hay alrededor de ellas, y también y especialmente la tecnología empleada. Se considera a menudo las fábricas como un vertebrador social del territorio, lo que es bien cierto, pero siempre se olvida que es un contenedor técnico: la sede de un negocio que emplea cierta tecnología para la producción. Cuando se habla de proteger una fábrica en realidad se quiere proteger un edificio, para vaciarlo y dotarlo de otro contenido.

El mundo del patrimonio industrial es un tanto singular. Cuando defendimos - y practicamos - la protección desde el área de etnología, en la Generalitat Valenciana, los autollamados arqueólogos industriales se sentían muy ofendidos, porque ellos no trataban con azadas o con alpargatas de esparto, sino con inmuebles potentes, con máquinas y con gente. Bien cierto que son campos diferentes, pero tampoco ellos practican la arqueología, entendida como método científico que utiliza sobre todo la excavación para la obtención de información de tiempos presentes o pasados.

En realidad la mal llamada arqueología industrial es una forma de recogida global de información, utilizando la palabra, el documento escrito o audiovisual, y muchos otros elementos, para recoger la vida global, en suma el patrimonio inmaterial de unos inmuebles en un momento dado de la historia.

Sólo conocemos un caso real de protección de patrimonio industrial - aunque no es menos cierto que se trata también de la protección del patrimonio inmaterial, es decir del conocimiento generado. Se trata del Museu Moli Paperer de Capellades ${ }^{7}$ que no solamente tiene una exposición permanente sobre la fabricación de papel y unas salas temporales para exposiciones relacionadas, sino que cuenta con una fábrica propia de papel, en la que es posible ver, e incluso aprender, la fabricación de papel con la técnica tradicional.

Por lo general las antiguas fábricas se reescriben, es decir se vacían de todo contenido, especialmente técnico, para convertirlas en contenedor, en un inmueble hermoso pero sin relación con su función original. Peor aún fue la declara-

7 La web oficial del Museu es http://www.mmp-capellades.net/spa/ (04-09-2018) 
ción genérica, en la modificación de la ley valenciana de $2007^{8}$, de las chimeneas de las fábricas anteriores a 1940 como Bien de Relevancia Local (el segundo nivel de protección del patrimonio), dejando fuera de protección el propio inmueble. Claro que la protección de las chimeneas, que todos daban por hecha, se justifica porque suponen un hito en el paisaje, ocupan poco espacio, apenas cuatro metros cuadrados, y son difíciles de demoler. Lo que no impide que se hayan desmontado y vuelto a erguir en otro lugar, cuando era urbanísticamente necesario.

Con el patrimonio industrial solamente se protege la apariencia, no el contenido ni el saber que hay detrás, y que es la clave para comprenderlo. Intentamos, sin éxito, en nuestro trabajo en la Generalitat, proteger un horno de cal, que existía en el propio término de la ciudad, y que fue prohibido porque hacían humo una vez al mes, cuando cocían la cal, y molestaba a los vecinos de una urbanización próxima. Tampoco pudimos proteger una fábrica de botijos de Agost, que aún deben seguir haciendo seis u ocho docenas de botijos por persona, cada día, pero que entonces aún se alimentaba por leña. Y fuimos incapaces de conservar en funcionamiento la fábrica de juguetes de chapa Payá, en Ibi.

En los tres casos se nos dijo que no podíamos intervenir, porque eran actividades privadas, y por tanto, la protección obligaba de cierto modo a seguir la actividad. Es un razonamiento perverso: cuando se protege un inmueble no se tiene en cuenta el propietario, sino el valor comunitario del mismo. Volveremos más adelante sobre el tema.

Es cierto que en el caso de la fábrica de Ibi se hizo un muy diseñado - y carísimo - museo que contiene juguetes, la mayor parte extranjeros, pues los Payá, a principios del XX, compraban dos juguetes de cada modelo, generalmente alemanes, ingleses o franceses, para desmontar uno de ellos y copiarlo, a menor precio, en sus instalaciones. Hay, pues, una preciosa colección de juguetes, mientras que, tras unas puertas herméticamente cerradas, la antigua maquinaria, que podría seguir trabajando, se está cayendo a trozos, abandonada, cuando hace apenas quince años seguía produciendo coches y trenes y maletas de lata.

Al final solamente se protegen las fiestas, precisamente aquello que necesita menos protección. En realidad tampoco se protegen las fiestas, por el contrario, en el momento de declararlas BIC Inmaterial, se crecen, se ordenan, se convierten

8 Disposición adicional quinta. Reconocimiento legal de Bienes Inmuebles de Relevancia Local, en atención a su naturaleza patrimonial. ... Punto 2 Los pozos o cavas de nieve o neveras, las chimeneas de tipo industrial construidas de ladrillo anteriores a 1940, los hornos de cal, los antiguos molinos de viento $y$ los antiguos molinos de agua, los relojes de sol anteriores al siglo XX, las barracas tradicionales propias de las huertas valencianas, las lonjas y salas comunales anteriores al siglo XIX, los paneles cerámicos exteriores anteriores a 1940, la arquitectura religiosa incluyendo los calvarios tradicionales que estén concebidos autónomamente como tales, asi como los elementos decorativos y bienes muebles relacionados directamente con el bien patrimonial a proteger. (Ley 5/2007, de 9 de febrero, de modificación de la Ley 4/1998, de 11 de junio, del Patrimonio Cultural Valenciano - BOE núm. 71 de 23-03-2007). 
en complejos fenómenos que más allá de buscar la cohesión social, de reconstruir la identidad local, buscan atraer turismo.

Y sin embargo la declaración de protección del patrimonio inmaterial hubiera supuesto, para estas tres empresas, no sólo una protección legal de sus actividades sino un reconocimiento social, que hubiera asegurado, sin duda el futuro de la producción.

Lo hemos dicho otras veces: el patrimonio no existe. El valor patrimonial es una especie de IVA, un valor añadido que le damos, a partir de una reflexión técnica y de una voluntad política a ciertos inmuebles, muebles o actividades de modo que la comunidad que los contempla, los mira con ojos nuevos. Y esta nueva mirada carga de valor, simbólico, identitario, patrimonial, y también económico, a los bienes protegidos.

\section{LA DECLARACIÓN DE LA UNESCO DE PATRIMONIO INMATERIAL}

Las fiestas no necesitan protección. El conocimiento que hay detrás de ciertas actividades, prácticas, conocimientos u oficios si que lo necesita. En estos momentos las fallas de València son Patrimonio de la Humanidad de la UNESCO. Yo escribí en su día que esa protección era innecesaria, porque las fiestas ya estaban suficientemente desarrolladas y vivas como para ser tuteladas ${ }^{9}$. Por supuesto me tildaron de ignorante, de mal patriota, de traidor incluso. Sin embargo, los antiguos conocimientos que había detrás, como la construcción de los ninots mediante escultura, molde y vaciado en cartón, por ejemplo, se han sustituido por el diseño en 3D, y la fabricación más o menos seriada de muñecos, ya no de cartón, sino de corcho blanco, que además arden de otro modo, produciendo más calor, olor y contaminación. Pero eso no importa, ya que las fallas son patrimonio mundial.

He hablado de la protección por la UNESCO: aquí ya tenemos unas cuantas fiestas protegidas como Patrimonio Mundial: el Misteri d'Elx (2001), la Patum de Berga (2005), los castells de Catalunya (2010), el Cant de la Sibil.la de Mallorca (2010), la festa de la Mare de Déu de la Salut d'Algemesi (2011), la fiesta de los patios de Córdoba (2012), las fiestas de fuego de los Pirineos (2015), las fallas de València (2016)

Dentro del patrimonio inmaterial puro protegido se encuentran el Silbo Gomero (2009), el Tribunal de las Aguas de València y los Hombres Buenos de Murcia (2009), el flamenco (2010), la dieta mediterránea (2010), la cetrería (2010), la cal artesanal en Morón de la Frontera $(2011)^{10}$.

9 LLOP i BAYO, Francesc Las fallas y el patrimonio mundial: ¿una protección innecesaria? "El Mundo" (10-03-2010) - Texto accesible en http://www.campaners.com/francesc.llop/text. php?numer=17 (04-09-2018)

10 https://es.wikipedia.org/wiki/Anexo:Patrimonio cultural inmaterial de la humanidad en Europa y Am\%C3\%A9rica del Norte\#Espa\%C3\%B1a Espa\%C3\%B1a (04-09-2018) 
Aparte de la última declaración, el resto es apariencia. $\mathrm{O}$ es fiesta, que viene a ser lo mismo. No hay conocimiento detrás, no hay conservación ni transmisión más que efímera. Y sin embargo todos quieren que su fiesta sea - si no lo es ya, porque muchos se autoatribuyen esa protección - Patrimonio Mundial de la Humanidad. Más, imposible.

Sin embargo, el procedimiento legal es complicado, y no se realiza a través de particulares, ni siquiera a través de los gobiernos autónomos, sino por petición del estado, es decir del Gobierno de España, fruto de un largo consenso previo entre las comunidades y el ministerio. Y España lo tiene difícil: de todos los estados miembros de la ONU, España figura la tercera con más bienes declarados (47) tras Italia (54) y China (53) en la lista de patrimonio mundial en $2018^{11}$.

\section{LA INDEFENSIÓN LEGAL}

Apuntamos anteriormente que el patrimonio mueble era algo así como el hermano menor del patrimonio: siempre prima, mental y legalmente, el patrimonio monumental, es decir el patrimonio inmueble. El patrimonio mueble, siempre considerado algo menor, como se puede desplazar, vender, robar... parece menos importante.

Pero con el patrimonio inmaterial, que debe referirse no sólo a las fiestas sino a los conocimientos de una, de cualquier comunidad en un momento de su historia, el desprecio es aún mayor, casi absoluto. Apuntábamos la práctica inexistencia de saberes conservados y protegidos, no sólo en la legislación sino en la aplicación concreta de la misma.

En un encuentro de la UNESCO en el que participamos en París hace unos años, comentaban los japoneses, entre saludos, que ellos solamente tenían 900 monumentos vivos, que es una feliz expresión para indicar aquellos conocimientos protegidos. Se trata de antiguos artesanos que no solamente siguen ejerciendo su oficio sino que lo transmiten a generaciones más jóvenes. Ciertamente ya no son artesanos como los antiguos: gran parte de su trabajo consiste en mostrar cómo lo hacen a los innumerables visitantes. Pero la protección legal, administrativa y económica, permite que sigan ejerciéndolo y mostrándolo, sin pérdidas económicas y con un creciente reconocimiento social. Y se quejaban los japoneses que, por la falta de presupuestos, no podían ampliar el número, y que los funcionarios dedicados a ello solamente podían visitar, a todos los monumentos vivos, un par de veces al año.

También Corea nos hablaba de una experiencia similar, con un número similar de monumentos vivos. Otra experiencia se estaba iniciando en Colombia y en Venezuela en aquellos años (2008-2010).

11https://es.wikipedia.org/wiki/Patrimonio de la Humanidad\#Estad\%C3\%ADsticas (0409-2018) 
Aquí, por el contrario, las consejerías de industria subvencionaban el cambio tecnológico de las pequeñas empresas artesanas para hacerlas más competitivas, sustituyendo hornos de leña por otros de gas, tornos por motores, o incluso por modelado en $3 \mathrm{~d}$. No hay ningún oficio, conocimiento, tecnología, protegidos, más allá de los hornos de cal de Andalucía, y también los toques de campanas de cuatro localidades en la Comunitat Valenciana. El resto son fiestas.

Ciertamente que estamos a favor del progreso. Incluso hemos ido muchas veces por delante ${ }^{12}$. Pero echamos en falta la preservación del antiguo conocimiento, de tantos antiguos conocimientos perdidos. Pusimos tres ejemplos valencianos: el horno de cal, la fábrica de botijos, la fábrica de juguetes de lata, tres ejemplos diversos de conocimiento tecnológico. Pero podría haber muchos más: no hay preservada una sola fábrica de cerámica con leña, las exhibiciones de oficios, que no están protegidas, son solamente eso, muestras, y no talleres de aprendizaje y producción permanente. Dicho de otro modo: si necesitamos restaurar una casa de adobe, o un telar, o un molino, no existen antiguos profesionales que no solamente vivan de su trabajo, sino que lo cuenten y lo transmitan. Porque además el concepto de artesano es ahora tan amplio y tan difuso que cualquiera que hace algo a mano ya es considerado como tal. Decimos manualmente, pero con tecnología actual: horno eléctrico, taladro motorizado o incluso ordenador que controla los tiempos. Nada del antiguo conocimiento tradicional.

Recordemos que el antiguo artesano (aprendiz, oficial, maestro...) controlaba todo un proceso, muchas veces desde la elaboración de la materia prima hasta la comercialización final. Ahora todos, incluidos nosotros, formamos parte de una cadena. No diseñamos, por supuesto, ni el ordenador, ni la programación, ni hacemos la tinta de la impresora, por poner casos cercanos. Pero un antiguo escritor se hacía su tinta, se preparaba sus plumas, y quizás compraba el papel, que unos artesanos habían elaborado completamente.

Claro que es divertido, un día al año, recordar como se hacía y si se cuenta con viejos artesanos aún vivos, les encantará tejer, segar, trillar o labrar un rato, para las fotos. ¿Pero dónde está ese conocimiento? ¿En los museos? A ellos les interesan los objetos, y últimamente, las anécdotas relacionadas (antes ni eso) pero no la técnica, el conocimiento que había detrás y que hemos dejado, voluntariamente, perder.

Desde nuestra jubilación, en 2014, nos dedicamos, casi exclusivamente, a mantener la citada página web campaners.com dedicada a campanas, campaneros y toques. Uno de los campos que genera más información es la denuncia contra los toques de campanas, considerado por muchos como patrimonio inmaterial,

12 Nuestra página Web http://campaners.com está en la red desde el 11-07-1996 cuando muchos no habían oído hablar de Internet. Del mismo modo, en nuestra tesis doctoral sobre los toques de campanas de Aragón (1988), en la que estudiamos diversos campaneros aragoneses entre 1983 y 1984 utilizamos el vídeo para su documentación, algo tan novedoso en aquel momento que muchos ignoraban que existía. 
pero por muchos otros como ruido. En realidad el ruido no existe. $\mathrm{O}$ mejor, ruido es lo que hacen los otros, como propuse, en un trabajo interdisciplinar sobre los sonidos tecnológicos tradicionales en España, que hicimos un equipo de cuatro personas para el Instituto de Acústica del CSIC entre 1985 y 1988, grabando diversos artesanos de norte a sur.

La idea no es peregrina: los otros, es decir los no nuestros, aquellos, los extraños. En el más de centenar de denuncias que hemos documentado contra los toques de campanas, no sólo nocturnos sino también diurnos ${ }^{13}$ siempre los denunciantes han sido forasteros, gente que llega a una comunidad y se molesta por los toques de campanas, que son habituales para los vecinos. Y siempre, el juez les ha dado la razón, acudiendo no a los aspectos patrimoniales del toque, sino al nivel sonoro producido. Al final parece que el denunciante, el otro, el recién llegado, ha actuado como un liberador que ha salvado a un pueblo oprimido por cadenas y por temores que no se atrevían a denunciar.

Incluso en Catalunya, con una protección genérica de las campanas, como vimos, los jueces utilizan el decibelímetro para evaluar el nivel sonoro, negando por la denuncia de uno el derecho de toda una comunidad.

Es relevante que no existe una sola denuncia contra el tráfico, exigiendo que pare de noche, mientras que son docenas las denuncias contra las campanas nocturnas. Aquí no sólo entran aspectos técnicos (nivel sonoro) sino inmateriales: el que denuncia, a menudo, está en contra del cura, del alcalde o de sus vecinos. Y el juez le da la razón.

Insistimos porque en el patrimonio inmueble ocurre todo lo contrario: el más sagrado de los derechos protegidos por la Constitución, el derecho de la propiedad, queda supeditado al valor patrimonial de un inmueble. Cuando un palacio, o un castillo, o una iglesia, o un simple hórreo, se declaran Bien de Interés Cultural con la categoría de monumento, el propietario, o mejor diríamos en términos administrativos el titular del inmueble, pierde gran parte de sus derechos en nombre de la comunidad. En menor medida ocurre lo mismo con el patrimonio mueble declarado. No puede venderlo, no puede restaurarlo, no puede modificarlo, sin el correspondiente permiso administrativo. No pierde su propiedad, pero ésta es limitada, de forma tajante, con el total consenso social.

Con el patrimonio inmaterial ocurre precisamente lo contrario. Cualquier norma legal inferior, como un reglamento de ruidos, sirve para defender los derechos de un particular en contra de la comunidad.

\section{PATRIMONio DE PRIMERA, DE SEGUNDA, DE TERCERA}

Incluso aunque la mayor parte de las leyes autonómicas permiten la protección del patrimonio inmaterial, incluso aunque el Ministerio de Cultural elaboró una

13 Ruido y denuncias: bibliografía general http://www.campaners.com/php/tema textos. php?numer=22 (04-09-2018) 
nueva ley propia del patrimonio inmaterial ${ }^{14}$, el patrimonio inmaterial es no tanto de segunda sino de tercera clase. La ley es bien curiosa porque parece más bien una declaración de intenciones: el preámbulo ocupa más de la mitad del texto, y hay una confusa Declaración de Manifestación Representativa del Patrimonio Cultural Inmaterial que compete al Ministerio en ausencia o por petición de Comunidad Autónoma, que no acaba de definir su nivel de protección, que no parece comparable al de Bien de Interés Cultural.

Es bien cierto que si a un político, o un gestor de bienes patrimoniales, le preguntamos si defiende el patrimonio, nos dirá sin dudar que lo defiende a capa y espada. Con lo patrimonial pasa lo mismo que con la modernidad o la europeidad: todos, especialmente los políticos son (¡somos?) modernos, europeos y defensores del patrimonio. Como me decía cierta vez un fundidor de campanas bienintencionado: he fundido dos campanas, he cambiado los yugos antiguos de madera por otros nuevos metálicos, he sustituido el reloj mecánico por un ordenador, he puesto motores y he programado toques nuevos, pero yo, el patrimonio, jlo conservo siempre! Hay que preguntarse qué queda del patrimonio original después de cambiarlo todo. Posiblemente esta sea la respuesta a una pregunta latente a lo largo de este discurso: queda la apariencia del patrimonio, porque no queremos, porque no necesitamos nada más.

Una vez decíamos, un tanto exageradamente, que para la mejor conservación de un monasterio, había que dejar dentro unas monjas para que vivieran allí. Otro tanto, y no menor, ocurre con todo el patrimonio inmaterial: ¿cuantos molinos, de viento o de agua se han restaurado en los últimos años? ¿Cuántos producen harina? Por que al final la respuesta está ahí: ¿cuánto patrimonio inmaterial existe realmente? Ciertamente, cualquier fábrica en funcionamiento es una sede de patrimonio inmaterial, al menos de conocimiento técnico. ¿Pero cuántas fábricas utilizan tecnología tradicional, que hemos protegido y que permitimos que sigan funcionando?

Decía el viejo maestro Marcel MAUSS en su Manual de Etnografía ${ }^{15}$, que tanto nos abrió los ojos, que se debía documentar cualquier trabajo, cualquier oficio, cualquier ritual, de modo que pudiéramos reproducirlo en el futuro sin que estuviesen sus actores. La documentación debía ser tan completa que incluyese no sólo palabras o gestos, sino también todo el conocimiento que hay detrás.

Ciertamente este es el ideal para transmitir no sólo unos inmuebles o unos objetos, sino un conocimiento, a veces reciente, a menudo secular, que llegó hasta nuestros días. Pero he de decir que, en la mayor parte de los casos, esos saberes,

14 Ley 10/2015, de 26 de mayo, para la salvaguardia del Patrimonio Cultural Inmaterial. BOE núm 126 de 27-05-2015

15 Se refiere a la transcripción de las clases que MAUSS dictó entre 1926 y 1939 en el Instituto de Etnología de la Université de Paris, del que hay múltiples ediciones tanto en español como en francés. 
que teníamos ante nuestros ojos, para los que disponíamos de la tecnología y de las herramientas conceptuales para recogerlos y transmitirlos, han desaparecido sin dejar rastro.

Quedan los objetos, muchas veces sin poderlos nombrar, porque perdimos las palabras, pero ¿qué sabemos de su uso, de su valor técnico y simbólico, de su transmisión? Al final solamente coleccionamos fachadas. Y las protegemos, pensando que hemos salvado la vida que había detrás. Y a menudo, detrás no hay nada, sino solamente un decorado que, eso sí, atrae turistas del mundo entero, atraídos por nuestra fama de contar con otro bien reconocido como Patrimonio Mundial por la UNESCO.

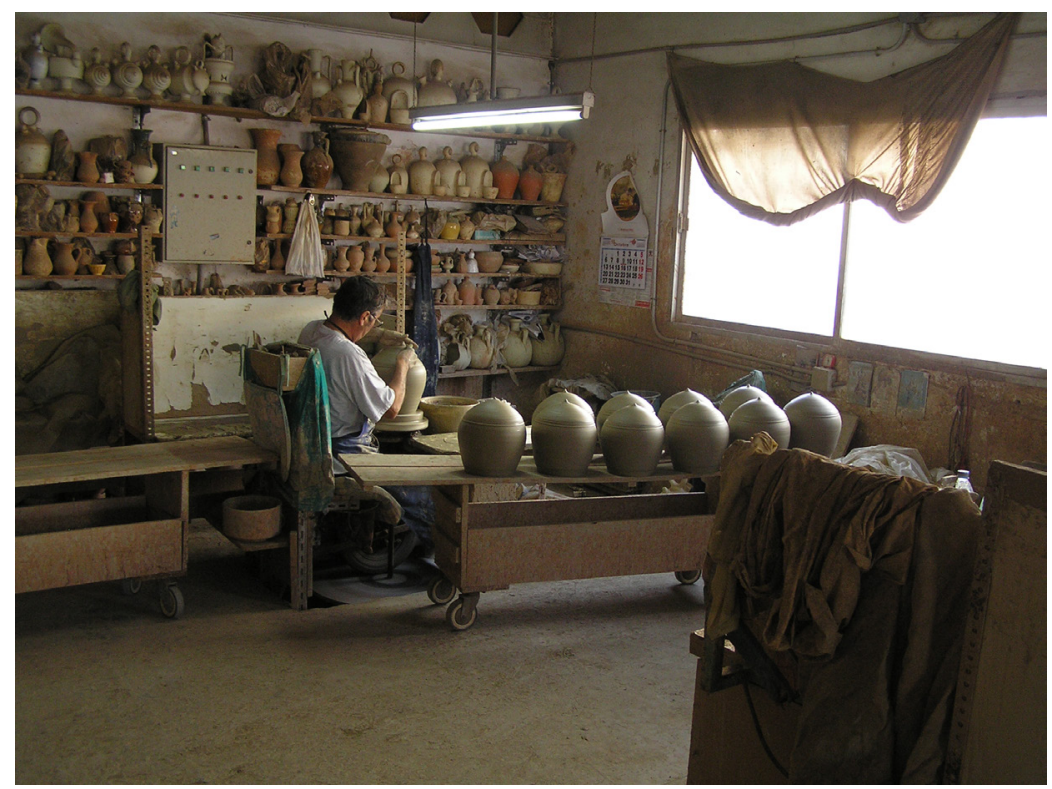

Cantereria La Navà (Agost - Comunitat Valenciana)

Foto LLOP i BAYO, Francesc (06-10-2008). 


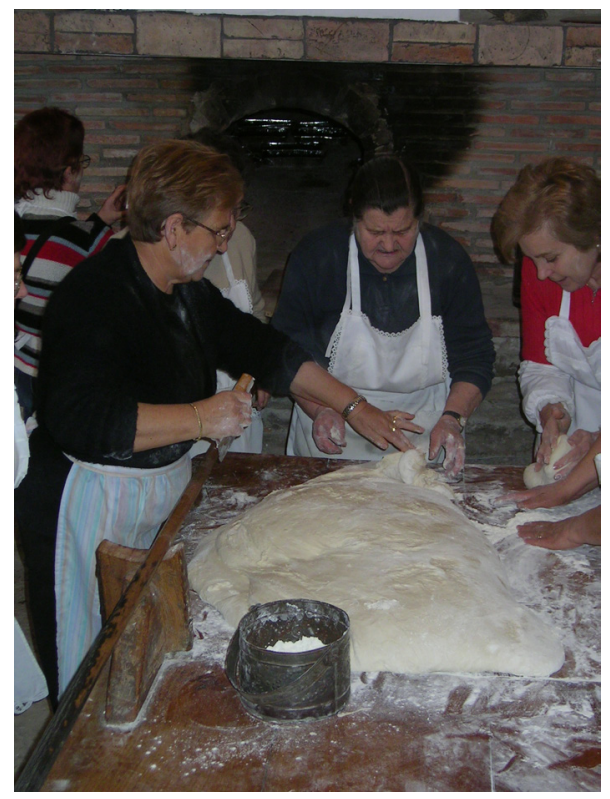

Preparando los panes de San Antón - Horno Comunitario de San Vicente de Piedrahita (Cortes de Arenoso - Comunitat Valenciana) Foto LLOP i BAYO, Francesc (14-01-2005).

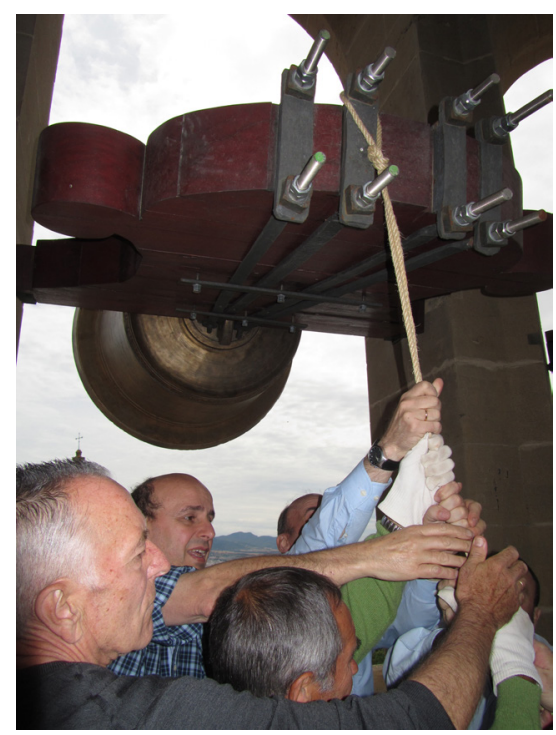

Curso de campaneros - Catedral de Pamplona (Navarra) Foto LLOP i BAYO, Francesc (12-06-2011). 